\title{
Marcel Proust, 4. Proust au tournant des siècles, I. Textes réunis par Bernard Brun et Juliette Hassine
}

\section{Emanuele Kanceff}

\section{(2) OpenEdition}

1 Journals

\section{Edizione digitale}

URL: https://journals.openedition.org/studifrancesi/38227

DOI: 10.4000/studifrancesi.38227

ISSN: 2421-5856

\section{Editore}

Rosenberg \& Sellier

\section{Edizione cartacea}

Data di pubblicazione: 15 décembre 2004

Paginazione: 644

ISSN: 0039-2944

\section{Notizia bibliografica digitale}

Emanuele Kanceff, «Marcel Proust, 4. Proust au tournant des siècles, I. Textes réunis par Bernard Brun et Juliette Hassine», Studi Francesi [Online], 144 (XLVIII | III) | 2004, online dal 30 novembre 2015, consultato il 08 mai 2021. URL: http://journals.openedition.org/studifrancesi/38227 ; DOI: https:// doi.org/10.4000/studifrancesi.38227

Questo documento è stato generato automaticamente il 8 mai 2021.

\section{(c) $($ ) $\odot$}

Studi Francesi è distribuita con Licenza Creative Commons Attribuzione - Non commerciale - Non opere derivate 4.0 Internazionale. 


\title{
Marcel Proust, 4. Proust au tournant des siècles, I. Textes réunis par Bernard Brun et Juliette Hassine
}

\author{
Emanuele Kanceff
}

\section{NOTIZIA}

AA. VV., Marcel Proust, 4. Proust au tournant des siècles, I. Textes réunis par Bernard BRUN et Juliette HASSINE, Paris-Caen, Lettres Modernes Minard, 2004 («La revue des Lettres Modernes», collection fondée et dirigée par Michel Minard. Éditeur de la Série Marcel Proust: Bernard Brun), pp. 291.

1 Segnaliamo questo numero della serie «Marcel Proust» diretta da Bernard Brun, che si presenta particolarmente ricco ed è frutto di un congresso internazionale tenutosi alla Bar-Ilan University (Israele) nel novembre 2001. In mancanza dello spazio necessario a commentare i vari interventi, ci sentiamo in dovere di segnalare almeno il contenuto in modo analitico.

Bernard BRUN, Avant propos (pp. 5-6); I: La génétique des textes: Nathalie MAURIAC DYER, M. de Lomperolles dans «Jean Santeuil» ou un aspect négligé de la genèse de Charlus (pp. 9-22); Mireille NATUREL, Le Fabuleux destin de l'article dans «Le Figaro» (pp. 23-40); Bernard BRUN, Sur quelques plaisanteries antisémites dans les manuscrits de rédaction de Proust (pp. 41-52); Jean-Marc QUARANTE, Génétique et intertextualité: pour une lecture épistémologique du corpus proustien (pp. 53-74); Françoise LERICHE, La Théorie esthétique proustienne à l'épreuve de la génétique (pp. 75-108); II. Sur la lecture: Thierry ALCOLOUMBRE, Aristote lecteur de Proust (pp. 111-132); Stéphane CHAUDIER, Proust et Boyleve: récits d'enfance entre deux siècles (pp. 133-144); Anne simon, Proust lecteur de Maeterlinck: affinités séclectives (pp. 145-160); Jo YOSHIDA, «Le Martyre de saint Sébastien» et Marcel Proust (pp. 161-174); Edward BIZUB, Proust et Joyce: une rencontre autour de l'épiphanie (pp. 175-186); Juliette HASSINE, Virginia Woolf et Marcel Proust: «remarques sur le style» (pp. 187-198); III. L'écriture infinie: Annick 
BOUILLAGUET, L'Écriture infinie (pp. 201-210); Helit YESHURUN, A la recherche de l'hébreu (pp. 211-222); Vera LASRY, Regards sur le corps humain dans l'écriture proustienne (pp. 223-234); Elisheva ROSEN, Mondanités proustiennes: le tournant de «Sodome et Gomorre» (pp. 235-248); Jean DELACOUR, Les réminiscences proustiennes et l'étude scientifique de la mémoire (pp. 249-272); Geneviève HENROT, L'Architecture du signe proustien (pp. 273-291). 